\title{
Individual differences in memory and the serial position effect
}

DENNIS M. ROBERTS, THE ONTARIO INSTITUTE FOR STUDIES IN EDUCATION ${ }^{1}$ Toronto 5, Canada AND LLOYD LEWIS INSTITUTE OF HUMAN LEARNING, FLORIDA STATE UNIVERSITY, Tallahassee, Fla. 32306

The present study investigated changes, if any, in the serial position curve when Ss were grouped on the basis of high to low recall scores. Ss received eight lists of verbal concept formation materials (Type I) for recall and cight weeks later, eight lists of nonsense syllables material (Type II) for recall. A group by serial position interaction was found for Type I but not Type II material. Diffcrential primacy-recency effects for the serial position curves were found for the two types of material. A correlation of .62 between performance on Type I and Type II material was obtained.

One aspect of individual differences in learning that has received attention relates to the serial position effect. McCrary \& Hunter (1953) showed that there was little difference in the serial curves between fast and slow learners, if the data were plotted in terms of percentages of errors for each group at each serial position. Noble \& Fuchs (1959) showed that fast learners tended to make relatively more errors in the middle of the list whereas slow learners tended to make more errors towards the extremes. Barnett, Ellis, \& Pryer (1960) found a superior IQ group made significantly more errors at Position 5 (in a 10 item list) and a low IQ group committed more errors at Position 2. Waugh (1960) presented a theory relating menory span to the serial position effect which involved a hypothesis concerning an interaction between Ss memory span and differential recall of sections of serial lists. Jensen \& Roden (1963), in Experiment 1, found no difference between high and low memory span groups on trials to criterion with the high span group making significantly fewer errors in the first four positions thereby indicating a difference in the skewness of the curves for the groups.

The present investigation was designed to further extend the serial position phenomenon into the area of individual differences. The main questions were: (1) Does the McCrary-Hunter hypothesis hold for a one trial short term memory task when using meaningful and nonsense verbal materials? (2) Is there any systematic change in the serial position curves when going from Ss who recall well to Ss who recall poorly? (3) What evidence is there for primacy and recency effects? and (4) What is the relationship between two kinds of short term memory tasks?

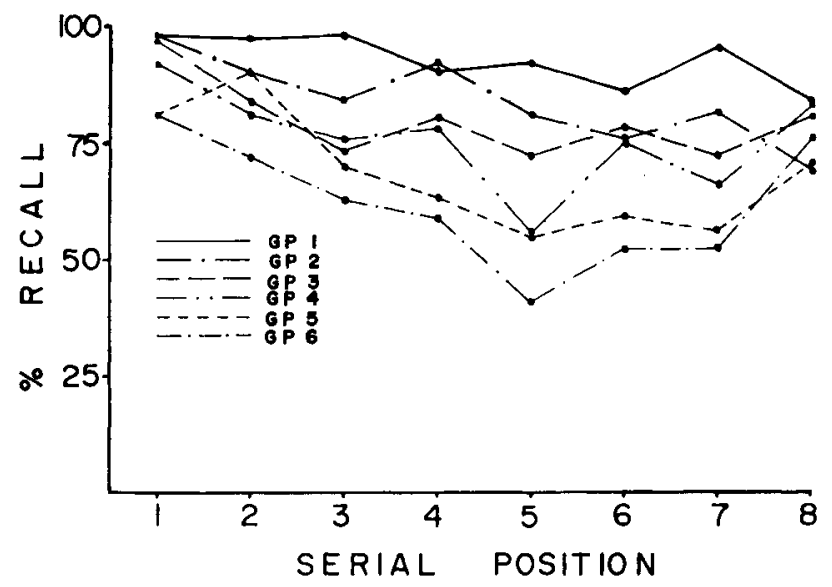

Fig. 1. Serial position curves for Type I material.

\section{Materials}

Two types of memory materials were used. Type I material, eight 8-item lists, was formed from Underwood \& Richardson's (1956) verbal concept formation materials. The words within four of the lists were arranged on a high, low, high, low dominance level value basis while the words within the other four lists utilized the opposite alternation pattern. In the statistical analyses, recall scores were summed over all eight lists. One example list was: cheese, spool, moss, mansion, flannel, atom, bone, and spinach. The mean dominance level value for each list ranged from 44 to 56. Type II material consisted of eight 8-item lists of nonsense syllables taken from Glaze (1928). High (100\%) and low (0-7\%) association value syllables were systematically varied across lists and serial positions like Type I material. The reasons for alternating dominance and association values within lists was relevant to a previous investigation (King, Reid, \& Roberts; 1966). Words in the lists for both types of material were printed on transparencies and shown by slide projector one word at a time.

\section{Procedure}

For Type I material, each word was individually flashed on the projection screen. The exposure interval was operated manually but was maintained at 1.5 to 2 sec. Following the complete presentation of a list, a blank slide would appear. This was the Ss' cue for recall. A $1 \mathrm{~min}$ recall interval was given. After the first list was finished, the remaining seven lists were presented in the same manner. This completed Session 1.

Session 2 came eight weeks after Session 1. The task was presented in the same manner as described for Type I material. Forty-five sec per list was given for recall.

\section{Subjects}

The Ss were taken from an undergraduate Educational Psychology class at Florida State University. During Session I, 48 Ss were tested while 42 of the above 48 were tested during Session II. Both males and females were included.

Results and Discussion

The normal procedure for plotting serial position curves was used in the present study. Analysis of variance was carried out to determine whether or not the McCrary-Hunter hypothesis was tenable. Figure 1 presents the serial position curves for Type I material. Ss were divided into six equal sized groups going from high to low recall scores. Notice that the serial position effect becomes more pronounced when going from the high to the low groups. The most interesting finding was the significant group by position interaction $(F=1.90 ; \mathrm{df}=35 / 2646 ; p<.01)$. This

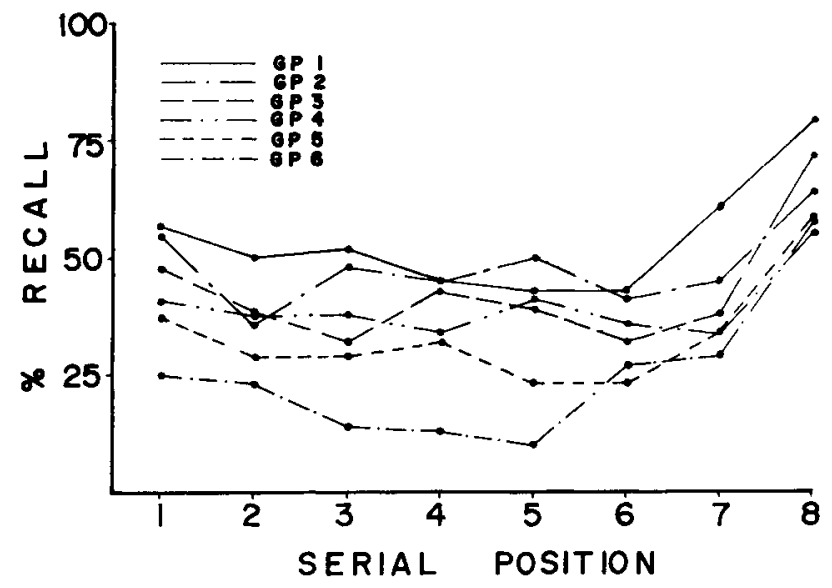

Fig. 2. Serial position curves for Type II material. 
Table 1

PR Scores for Types I and II Material

\begin{tabular}{ccc} 
& \multicolumn{2}{c}{ PR Scores } \\
\cline { 2 - 3 } Group & Type I & Type II \\
\hline 1 & 14 & -22 \\
2 & 29 & -9 \\
3 & 17 & -23 \\
4 & 9 & -14 \\
5 & 11 & -23 \\
6 & 6 & -32 \\
Mean & 14.33 & -20.50 \\
\hline
\end{tabular}

indicates that the serial position curve was more pronounced in some groups than in others. This result would seem to be contrary to what McCrary-Hunter found since the shapes of the curves are dissimilar. Correcting for overall recall differences in each group would not alter the pattern of the curves.

Figure 2 presents the serial position curves for the six groups of Ss going from high to low recall scores for Type II material. In this analysis, the group by position interaction was not significant.

According to Deese (1958), free recall procedures usually produce recency rather than primacy effects. The present investigation offers both supporting and contradictory evidence to this generalization. The primacy-recency effects can be indexed by arbitrarily subtracting the per cent recall on the last position from the per cent recall on the first position. Therefore, $P R=$ primacy-recency. Thus it can be seen that if $P R$ is positive then primacy effects were obtained whereas if it is negative then recency effects were obtained. Table 1 presents the PR scores for each of the six groups for both types of memory material. Notice that with Type I material there is a primacy effect while an even stronger recency effect was found for the Type II material.

The last aspect of the results relates to the correlation between the two memory tasks. Based on a sample of 42 cases that took both types of memory material, the correlation between Type I and Type II material was .62 $(p<.01)$. This indicates, in terms of recall, that the rank of Ss tends to be similar for both meaningful and nonsense memory materials used in the present study.

\section{REFERENCES}

BARNETT, C. D., ELUIS, N. R., \& PRYER, M. W. Serial position effects in superior and retarded subjects. Psychol. Rep., 1960, 7, 111-113.

DEESE, J. The psychology of learning. (2nd ed.) New York: McGraw-Hill, 1958

GLAZE, J. A. The association value of nonsense syllables. J. genet. Psychol. $1928,35,225-267$.

JENSEN, A. R., \& RODEN, A. Memory span and the skewness of the serial position curve. Brit. J. Psychol., 1963, 54, 337-349.

KING, F. J., REID, I., \& ROBERTS, DENNIS M. Free recall of intra-list items as a function of serial position, association value and conceptualization. Psychon. Sci, 1966, 4, 311-312.

MCCRARY, J. W., \& HUNTER, W. S. Serial position curves in verbal learning. Science, 1953, 117, 131-134.

NOBLE, C. E., \& FUCHS, J. E. Serial errors in human learning: A test of the McCrary-Hunter hypothesis. Science, 1959, 129, 570-571.

UNDERWOOD, B. J., \& RICHARDSON, J. Some verbal materials for the study of concept formation. Psychol. Bull., 1956, 53,84-95.

WAUGH, N. C. Serial position and the memory span. Amer. J. Psychol, $1960,73,68-79$.

\section{NOTE}

1. Part of the work for this study was completed by this author while at Florida State University. 